\title{
Identification of indigo-related pigments produced by Escherichia coli containing a cloned Rhodococcus gene
}

\author{
Stephen HaRt, ${ }^{1}$ Klaus R. Koch ${ }^{2}$ and David R. WoOds ${ }^{1 *}$ \\ ${ }^{1}$ Department of Microbiology and ${ }^{2}$ Department of Chemistry, University of Cape Town, Rondebosch, 7700, South Africa
}

(Received 10 June 1991; revised 30 August 1991; accepted 16 September 1991)

\begin{abstract}
Pigments produced by Escherichia coli containing a cloned piece of DNA from Rhodococcus sp. ATCC 21145 were extracted in chloroform and separated into blue and pink components. Evidence from TLC, NMR spectroscopy, absorption spectrum analysis and solubility behaviour suggested that the blue pigment was indigo and the pink pigment was indirubin, a structural isomer of indigo. The proposed pathway for pigment production on LB agar involves the conversion of tryptophan to indole by tryptophanase of $E$. coli and the oxidation of indole to indigo by the product of the cloned Rhodococcus DNA insert.
\end{abstract}

\section{Introduction}

We previously reported the cloning and sequence determination of a Rhodococcus gene which stimulated the production of pink and blue water-insoluble pigments in Escherichia coli (Hill et al., 1989; Hart et al., 1990). Pigment production depends on a single open reading frame of $1163 \mathrm{bp}$ with the coding capacity for a protein with an $M_{\mathrm{r}}$ value of 42560 which could be visualized in an in vitro transcription-translation experiment. Database searches revealed no protein or DNA sequences with pronounced similarity to the cloned Rhodococcus gene. This study identifies the blue and pink pigments as indigo and indirubin, respectively. Both pigments are derived from indole. No indigo production could be detected in Rhodococcus. The 'indigo gene' has been utilized in the construction of an attractive alternative to $l a c Z^{\prime} \alpha$-based cloning vectors because it does not require specifically mutated host strains or an expensive substrate for colour development (Hart \& Woods, 1992).

\section{Methods}

Bacterial strains, plasmids and media. The bacterial strains used in these studies, listed in Table 1, were routinely propagated on LB agar (Maniatis et al., 1982). Minimal medium (MM) (Miller, 1972) contained $0.2 \mathrm{mg}$ lactose $\mathrm{ml}^{-1}$ (lac). Tryptophan and indole (Sigma) were added to media at a final concentration of $1 \mathrm{~mm}$, and ampicillin (Ap) at $100 \mathrm{mg} \mathrm{ml}^{-1}$.

Abbreviations: Ap, ampicillin; DMSO- $d_{6}$, deuterated DMSO [( $\left.\left.\mathrm{CD}_{3}\right)_{2} \mathrm{SO}\right]$; lac, lactose; $\mathrm{MM}$, minimal medium; Pig, pigment production.
Table 1. Bacterial strains and plasmids

\begin{tabular}{|c|c|c|}
\hline $\begin{array}{l}\text { Strain or } \\
\text { plasmid }\end{array}$ & $\begin{array}{l}\text { Genotype or } \\
\text { phenotype }\end{array}$ & $\begin{array}{l}\text { Source or } \\
\text { reference }\end{array}$ \\
\hline E. coli 3.300 & $\begin{array}{l}\text { lacI22 } \lambda^{-} \text {relAl, } \\
\text { spoTl thi-l }\end{array}$ & Pardee et al. (1959) \\
\hline E. coli LK 111 & lacl lacZ $\Delta \mathrm{M} 15$ lac $Y^{+}$ & Zabeau \& Stanley (1982) \\
\hline E. coli MY252 & $t a^{+} \triangle \operatorname{trp} A C 9$ & M. Yudkin, Oxford, UK \\
\hline E. coli MY1393 & tna $103 \triangle \operatorname{trp} A C 9$ & M. Yudkin, Oxford, UK \\
\hline Rhodococcus sp. & Wild-type & ATCC 21145 \\
\hline $\begin{array}{c}\text { ATCC } 21145 \\
\text { Rhodococcus sp. }\end{array}$ & & \\
\hline JL10 & Wild-type & Hill et al. (1989) \\
\hline $\mathrm{pKSI}$ & Ap $^{r}$ LacZ $^{-}$ & Hart et al. (1990) \\
\hline pNC185 & Ap $^{r}$ LacZ $^{-}$Pig $^{+}$ & Hart et al. (1990) \\
\hline $\mathrm{pNC} 181$ & $\mathrm{Ap}^{r} \mathrm{LacZ}^{-} \mathbf{P i g}^{+}$ & Hart et al. (1990) \\
\hline pUC18 & $\mathrm{Ap}^{r} \mathrm{LacZ}^{+}$ & Vieira \& Messing (1982) \\
\hline
\end{tabular}

Identification of pigment producing clones. Blue to blue-grey pigmentproducing $E$. coli colonies were observed after overnight incubation at $37^{\circ} \mathrm{C}$ followed by $8-24 \mathrm{~h}$ incubation at room temperature.

Pigment preparation. Pigments were extracted in chloroform as described by Hill et al. (1989).

TLC. Preparative TLC was performed to purify the pigment components from crude chloroform extracts using chloroform as the chromatographic solvent. Samples of the pigmented chloroform extract were applied repeatedly across the width of the plate (Merck cat. no. 5717 , PLC silica gel $60 \mathrm{~F}_{254}, 20 \mathrm{~cm} \times 20 \mathrm{~cm}, 2 \mathrm{~mm}$ thick). Each application was allowed to dry completely before the next one was applied. The chromatographs were resolved by standing the plates in a glass chromatographic tank containing a saturated atmosphere of chloroform and a small volume of chloroform so that the solvent was in contact with the silica stationary phase. The crude pigment extract separated into pink- and blue-pigmented bands within $40 \mathrm{~min}$. After drying the plates, the silica containing the pigment bands was cut and scraped from the TLC plate, crushed to a fine powder and poured into a glass bottle containing chloroform. The silica slurry containing the 
pigments was shaken vigorously for $1 \mathrm{~h}$ to allow the pigments to elute into the chloroform. The silica was removed by filtration in a Buchner funnel, washed with fresh chloroform and the purified pigment concentrated by evaporation of the combined chloroform washings. Purified pigment fractions were dissolved in DMSO- $d_{6}$ for analysis by NMR spectroscopy.

Analytical TLC was performed on silica plates (Merck cat. no. 16485 , silica gel $60 \mathrm{~F}_{254}, 20 \mathrm{~cm} \times 20 \mathrm{~cm}, 0.25 \mathrm{~mm}$ thick). Samples were applied as small spots along a reference line and commercial indigo (Sigma) in chloroform $\left(0.5 \mathrm{mg} \mathrm{ml}^{-1}\right)$ was used as a control.

NMR spectroscopy. ${ }^{1} \mathrm{H}$ and ${ }^{13} \mathrm{C}$ spectra were obtained at 200 and $50.32 \mathrm{MHz}$, respectively, using a Varian VXR-200 spectrometer at $25^{\circ} \mathrm{C}$. The pigments were dissolved in DMSO- $d_{6}$.

Absorption spectra of the pigments. The visible light absorption spectra $(400-800 \mathrm{~nm})$ of TLC-purified and unpurified bacterial pigment samples and an indigo control sample were determined by scanning in a Beckman DU-40 spectrophotometer attached to an Epson FX-80 printer.

Solubility of the pigments. Freshly prepared bacterial pigment extracts in chloroform were evaporated until dry, resuspended in a range of organic solvents (acetone, chloroform, 1,2-dichloroethane, DMSO, ethanol, ethyl acetate, ethylmethylketone, glacial acetic acid, methanol, octane, toluene and xylene) and their solubility and appearance compared to that of commercial indigo.

Transformation of $E$. coli strains. The $E$. coli tryptophanase-negative strain MY1393 and its wild-type parent strain MY252 (Table 1) were both transformed with plasmids pNC185 and pUC18 by the method of Chung \& Miller (1988).

RNA dot blot analysis. RNA was extracted from $E$. coli and Rhodococcus strains by the method of Alba et al. (1981). RNA dot blots were performed on Hybond- $\mathrm{N}$ nylon membranes according to the manufacturer's instructions ('Blotting and hybridization protocols for Hybond membranes', Amersham). RNA from E. coli LK 111 containing pUC18 and pNC181, Rhodococcus sp. ATCC 21145 and Rhodococcus sp. JL10 was heated to $90^{\circ} \mathrm{C}$ for $2 \mathrm{~min}$, cooled on ice and applied in spots containing 2, 5 and $10 \mathrm{mg}$ RNA onto Hybond-N (Amersham) nylon membrane which was sealed in a vacuum dotolotting apparatus. The nylon membrane was then dried and fixed on a UV trans-illuminator as described by the manufacturer (Amersham).

Two probes, the whole pUC18 plasmid and the HindIII/BgIII DNA fragment of the Rhodococcus insert from the pigment-producing plasmid pKSI (Hart et al., 1990) were radioactively labelled using a nick translation kit following the manufacturer's instructions (N . 500, Amersham). The probes were labelled with $\left[\alpha-{ }^{32} \mathrm{P}\right] \mathrm{dCTP}$ with a specific activity of $3000 \mathrm{Ci} \mathrm{mmol}^{-1}$ (Amersham). Hybridization was carried out at $65^{\circ} \mathrm{C}$ for $12 \mathrm{~h}$ and the filters were washed under stringent conditions following the manufacturer's instructions (Amersham). Membranes were dried and exposed to X-ray film (Curix, Agfa) for 18-24 h.

\section{Results}

\section{Minimal media supplementation}

Colonies of $E$. coli $3.300(\mathrm{pNC1} 185)$ produced copious amounts of blue pigment on LB Ap agar plates but were unpigmented on MM Ap lac plates. Addition of L-tryptophan or indole to the MM Ap lac plates resulted in copious blue pigment formation. Other amino acids (L-alanine, L-arginine, cysteine. $\mathrm{HCl}$, L-glutamic acid,
L-glycine, L-histidine, L-leucine, L-methionine, D,Lphenylalanine, L-proline, L-serine, L-threonine, L-tyrosine or D,L-valine) supported growth of both $E$. coli strains but all colonies were white. $E$. coli 3.300( $\mathrm{pNC185}$ ) and 3.300(pUC18) were grown on MM lac Ap plates containing $1 \mathrm{mM}$-indole but only $E$. coli $3.300(\mathrm{pNC} 185)$ produced blue pigment which suggested that both indole and pNC185 are required for pigment formation. These results suggested that the blue pigment may be derived from indole, a metabolite of tryptophan, which is known to have many pigmented derivatives (Ensley et al., 1982). E. coli converts tryptophan to indole by the action of tryptophanase (Botsford \& DeMoss, 1971; Ward \& Yudkin, 1976).

\section{Transformation of a tryptophanase-negative strain of E. coli}

E. coli MY1393 ( $\triangle$ trpAC9, tna 103) has a growth requirement for tryptophan but does not produce tryptophanase and therefore cannot produce indole from tryptophan, whereas the parent strain, MY252 $\left(\triangle \operatorname{trp} A C 9, \operatorname{tna}^{+}\right)$only has the tryptophan growth requirement and is wild-type with regard to tryptophanase activity. It was expected that if indole was required for pigment biosynthesis that the tna mutant strain, MY1393, transformed with pNC185 would be nonpigmented whereas MY252 $\left(\right.$ tna $\left.^{+}\right)(\mathrm{pNC185})$ would be pigmented. The phenotype of each strain was checked by attempting to grow the strains on $\mathrm{MM}$ agar containing tryptophan as the sole carbon and energy source, for which tryptophanase is required. Only strain MY252 $\left(\mathrm{tna}^{+}\right)$was able to grow under these conditions. Competent cells of both strains were prepared and transformed with plasmids $\mathrm{pUC1} 18$ and $\mathrm{pNCl} 85$. Transformants were selected on LB Ap agar and tested for pigment production. As expected, strain MIY1393 $\left(\right.$ tna $\left.^{-}\right)$transformed with both pUC18 and pNC185 was nonpigmented as was MY252 $\left(t^{+} a^{+}\right)$containing pUC18. Strain MY252 transformed with pNC185, however, produced blue-pigmented colonies. This result suggested that tryptophanase was important for pigment production from tryptophan. E. coli MY1393(pNC185) grown on LB Ap agar plates containing $1 \mathrm{~mm}$-indole gave a low level of pigment production [much less than obtained from $E$. coli MY252(pNC185)] confirming that indole is a precursor for pigment formation.

\section{Rhodococcus growth experiments}

Rhodococcus sp. ATCC 21145 and Rhodococcus sp. JL10 grown on LB agar, LB agar containing $1 \mathrm{~mm}$-indole and $1 \mathrm{~mm}$-tryptophan or in LB broth containing $1 \mathrm{~mm}$-indole did not produce blue pigment within $5 \mathrm{~d}$ incubation at $30^{\circ} \mathrm{C}$. 


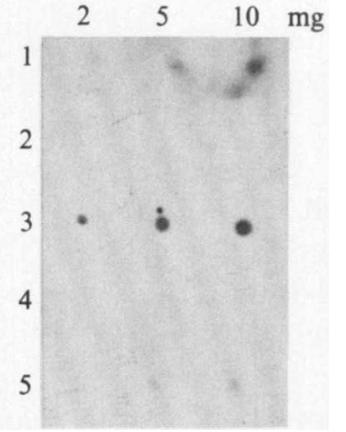

Fig. 1. Detection of RNA homologous to the Rhodococcus pigment producing gene. RNA samples $(2,5$ and $10 \mathrm{mg}$ each) were loaded onto the membrane and probed with the HindIII/BglII fragment of the Rhodococcus pigment-producing insert in pKS1 unless stated otherwise. 1, E. coli LK111(pUC18) probed with pUC18 DNA; 2, E. coli LK111(pUC18); 3, E. coli LK111(pNC181); 4, R. corallinus JL-10; 5, Rhodococcus sp. ATCC 21145.

\section{RNA dot blot analysis}

The aim of this experiment was to establish whether or not the Rhodococcus gene contained within the pigmentproducing DNA insert in $E$. coli plasmids such as pNC1 85 was being expressed in the original Rhodococcus sp. since it did not produce detectable amounts of the blue pigment. The positive control probe, the plasmid pUC18, hybridized strongly with RNA from $E$. coli LK111(pUCl8) (Fig. 1). The negative control, the HindIII/BglII fragment from the Rhodococcus DNA insert in pKS1, failed to hybridize with the same RNA. The RNA from $E$. coli LK111(pNC181) hybridized strongly with the HindIII/Bg/II Rhodococcus DNA fragment, as expected. RNA from Rhodococcus sp. ATCC 21145 hybridized weakly with the HindIII/BglII fragment whereas RNA from another Rhodococcus strain, Rhodococcus sp. JL10, showed no hybridization signal at all with the same probe under stringent hybridization and washing conditions. These results suggested that the same DNA insert which was transcribed and caused pigmentation in recombinant $E$. coli was also transcribed in Rhodococcus sp. ATCC 21145 but did not enable detectable pigment formation in this bacterium.

\section{$T L C$}

Samples of pigmented bacterial chloroform extracts were analysed by TLC and compared with a sample of authentic indigo in chloroform. The bacterial pigment separated into a faster moving blue component and a slower moving pink component.

The indigo sample contained a predominant blue component with the same mobility as the blue compo- nent of the bacterial pigment extract $\left(R_{F}=0 \cdot 21\right)$ and a very faint pink component with the same mobility as the pink bacterial pigment $\left(R_{F}=0.07\right)$. It was observed that in freshly prepared bacterial pigment extracts the blue component was predominant but in older extracts the pink fraction increased in concentration relative to the blue fraction. The chromophores were not interconvertible but the blue chromophore changed into the pink form and not vice versa.

\section{Pigment absortion spectra}

The absorption spectra of pigment solutions in chloroform purified by preparative TLC were determined. The blue pigment had an absorption peak at $602 \mathrm{~nm}$ whereas the pink pigment absorbed light most strongly at $552 \mathrm{~nm}$. The absorption spectrum of a chloroform solution of indigo was similar to that of the blue bacterial pigment and also had an absorption peak at $602 \mathrm{~nm}$. The absorption spectrum of a freshly extracted, pigmented chloroform solution which had not been separated by TLC, had a major absorption peak at $602 \mathrm{~nm}$ with a shoulder in the peak at $560 \mathrm{~nm}$ which was presumably caused by the combination of the pink and blue pigments in the same solution. The unpurified pigment extract was allowed to stand at room temperature overnight for about $16 \mathrm{~h}$ after which time the pigment extract had taken on more of a purplish hue. An absorption spectrum showed that the predominant absorption peak had shifted to $552 \mathrm{~nm}$ and a shoulder was apparent at $600 \mathrm{~nm}$. This observation suggested that the blue pigment was slowly being converted into the pink pigment on standing in the crude bacterial chloroform extract.

The TLC-purified pink and blue pigments appeared to be stable in chloroform. An authentic sample of indigo was dissolved in a non-pigmented chloroform extract of $E$. coli $\mathrm{LK} 111$ (pUC18) and left at room temperature for $16 \mathrm{~h}$. However, no change was seen in the absorption spectrum of the indigo solution.

These results suggested that the blue bacterial pigment may be indigo or an indigo-related compound and that the pink pigment was chemically related to the blue pigment.

\section{Solubility behaviour of the pigments}

A freshly prepared, pigmented chloroform extract from $E$. coli LK111(pNC185) grown in LB broth was evaporated and redissolved at room temperature in a range of solvents. The pigment was insoluble in water, ethanol, methanol and octane, slightly soluble with a reddish colour in both xylene and toluene, and very 


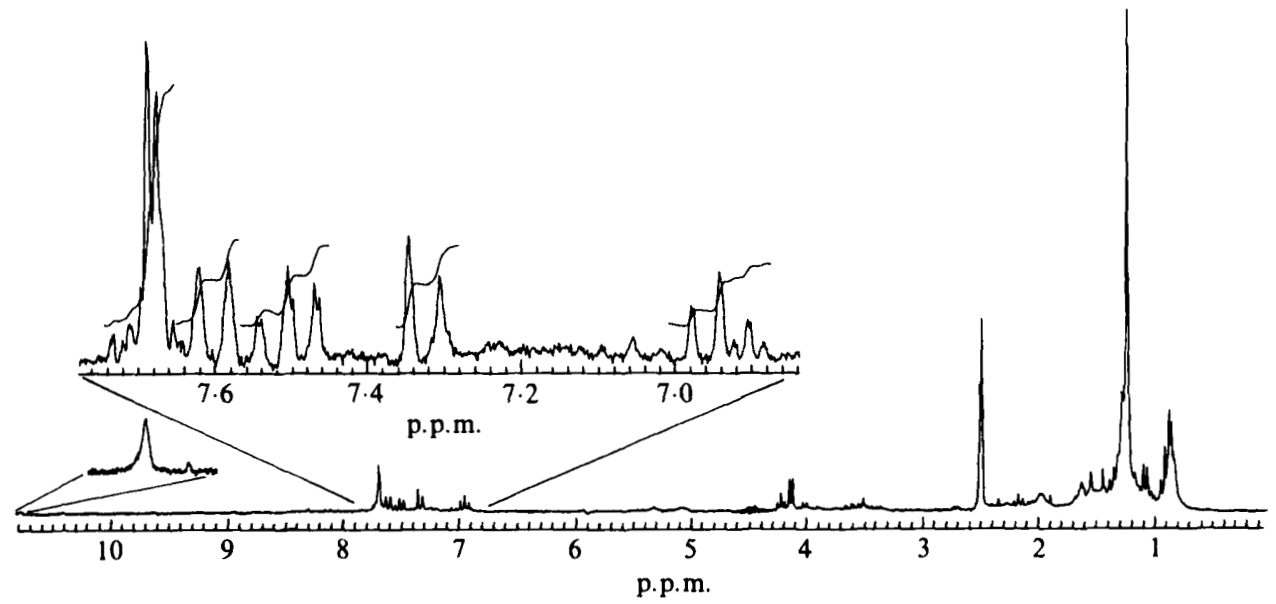

Fig. 2. 'H NMR spectrum of the blue pigment (purified by TLC) in DMSO- $d_{6}$. The residual water resonance at approximately 4.4 p.p.m. is removed by selective saturation. soluble in acetone (reddish blue solution), chloroform (purple solution), 1,2-dichloroethane (red solution), ethylmethylketone (reddish blue solution) and glacial acetic acid (reddish blue solution). The solvent in which the pigment was most soluble was the highly polar organic solvent DMSO which dissolved the pigment to give a deep azure-blue solution. Indigo had similar solubility properties although the colours of the bacterial pigment solutions were more red in solvents such as acetone, possibly due to the greater proportion of pink pigment in the unpurified bacterial pigment extract than in commercial indigo.

Adjustment of the $\mathrm{pH}$ had no affect on the colour of purified blue and pink pigments.

\section{NMR spectroscopy}

A $200 \mathrm{MHz}{ }^{1} \mathrm{H}$ NMR spectrum of the blue pigment (purified by TLC) in DMSO- $d_{6}$ is shown in Fig. 2. It is clear that a substantial amount of aliphatic material is associated with this pigment, despite chromatographic purification of this substance. This suggests that the blue chromophore is either chemically attached to the aliphatic material or the blue pigment is a complex conjugate of the chromophore and the aliphatic material. Nevertheless, the expanded region of the ${ }^{1} \mathrm{H}$ spectrum of the blue pigment is consistent with the proposition that the blue pigment is an indole-based pigment, presumably indigo (Fig. 3). This conclusion is based on the indoletype $\mathrm{N}-\mathrm{H}$ resonance at 10.45 p.p.m. (cf. authentic indole in DMSO- $d_{6}, 11.08$ p.p.m.; tryptophan, 11.03 p.p.m.) and the four-spin $A^{\prime} A^{\prime} B^{\prime}$ structure of the spectrum in the 6.5-7.7 p.p.m. region expected for an indole-based pigment. The resonance centred at 7.66 p.p.m. is not clearly correlated to any of the other resonances at 7.63(d), 7.50(t), 7.32(d) and 6.94(t) p.p.m. as observed in the two-dimensional homonuclear correlation (COSY) spectrum, suggesting that the 7.66 resonance is not

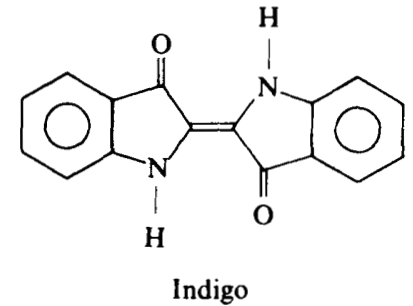<smiles>O=C1Nc2ccccc2/C1=C1/Nc2ccccc2C1=O</smiles>

Indirubin

Fig. 3. Structural formulae of indigo and indirubin.

directly associated with the blue chromophore. Surprisingly, it was not possible to obtain a ${ }^{1} \mathrm{H}$ spectrum of authentic indigo (Sigma) in DMSO- $d_{6}$. All attempts in this regard failed, the resonances being extremely broadened, presumably by some paramagnetic species associated with the authentic sample of indigo. It is possible that the intense colour of the authentic indigo may be associated with a stable free radical, a question deserving further investigation. Unfortunately, attempts to obtain a ${ }^{13} \mathrm{C}$ NMR spectrum of the blue pigment was rewarded only by a very poor spectrum partly due to the low concentration of the pigment (3-5 $\mathrm{mg} \mathrm{ml}^{-1}$ ), as well as the apparent instability of the pigment during spectral acquisition. No conclusions could be drawn from this spectrum.

The solution of blue pigment in DMSO- $d_{6}$ changes to a 


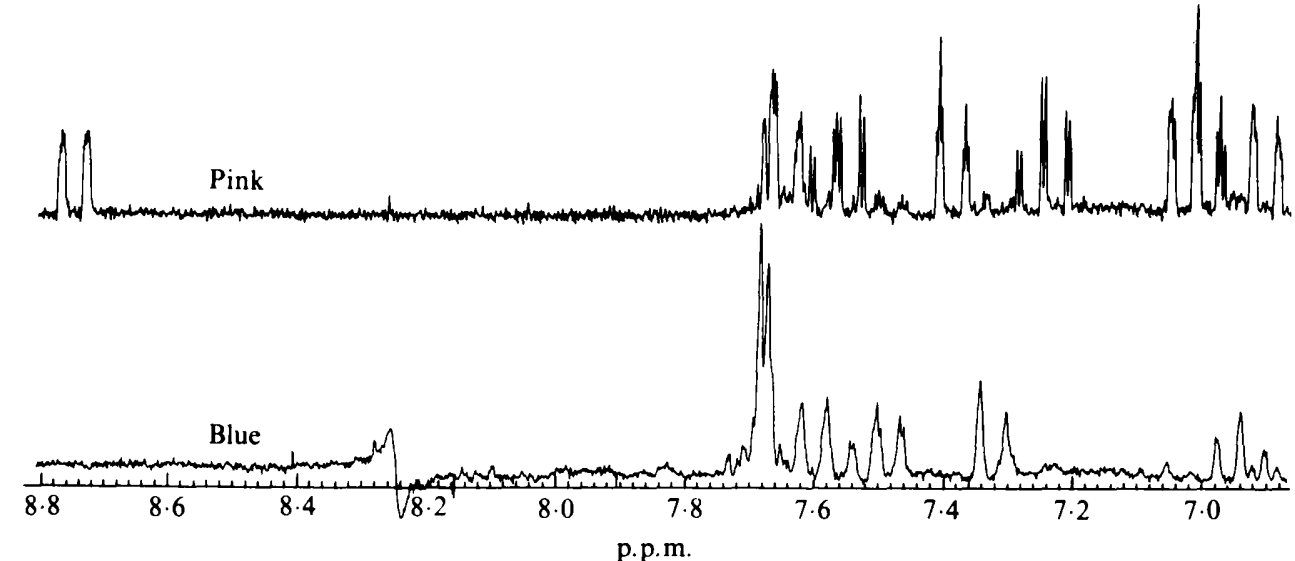

Fig. 4. Expanded ${ }^{1} \mathrm{H}$ NMR of the blue and pink pigment in DMSO- $d_{6}$ recorded at $40^{\circ} \mathrm{C}$. pink colour relatively rapidly, with the result that during spectral acquisition these changes complicate the ${ }^{1} \mathrm{H}$ and ${ }^{13} \mathrm{C}$ NMR spectra. Nevertheless, a ${ }^{1} \mathrm{H}$ spectrum of the pink pigment is substantially different from that of the blue pigment, the spectrum of the former usually showing some contamination with the blue chromophore, as may be seen in Fig. 4. The ${ }^{1} \mathrm{H}$ spectrum of the pink pigment has two equally intense indole-type $\mathrm{N}-\mathrm{H}$ resonances at 10.82 and 10.98 p.p.m. (not shown in Fig. 4) in addition to at least three sets of triplets and four sets of doublets. Although this spectrum does not have a simple first order structure, the spectrum is consistent with a possibility that the pink pigment may be indirubin, a structural isomer of indigo (Fig. 3). It should be noted that indirubin may itself consist of at least two isomers, so potentially complicating the ${ }^{1} \mathrm{H}$ spectrum. An unambiguous assignment is not possible with the present data.

In view of the relatively high stability of the pink form of the pigment, a ${ }^{13} \mathrm{C}$ NMR spectrum could be recorded showing at least ten carbon resonances in the 100170 p.p.m. range, seven of which have an $\mathrm{H}$ atom attached. Although the quality of the ${ }^{13} \mathrm{C}$ spectrum was not sufficient for a complete assignment, these preliminary results are consistent with the proposed structure of the pink chromophore probably being indirubin.

\section{Discussion}

It is proposed that the blue component of a pigment produced by $E$. coli containing a cloned Rhodococcus gene is indigo and that the pink component is indirubin, an isomer of indigo. The biosynthetic pathway probably involves the enzymic conversion of tryptophan to indole by tryptophanase of $E$. coli, followed by the oxidation of indole by the product of the cloned Rhodococcus gene in $E$. coli. Evidence for this hypothesis consisted of the following observations.
(1) Tryptophan and indole were shown to be precursor substrates for pigment production by $E$. coli containing pigment-producing plasmids on minimal medium. This suggested that indigo was being produced by the pathway suggested by Ensley et al. (1982) in which tryptophan was converted to indole by the constitutively expressed tryptophanase gene, tna, of $E$. coli and indole was then oxidized by the cloned gene product, naphthalene dioxygenase, to indoxyl which underwent autoxidation in air to indigo. The conversion of tryptophan to indole by $E$. coli was demonstrated to be a step in the pathway to pigment production by transformation of $\mathrm{pNC185}\left(\mathrm{Pig}^{+}\right)$into a tryptophanase-negative $E$. coli strain which failed to produce pigments.

(2) A tryptophanase-negative E. coli strain, MY1393, which was unable to produce indole from tryptophan, was non-pigmented when transformed with the pigment-producing plasmid $\mathrm{pNCl} 85$.

(3) The blue pigment and indigo had identical $R_{F}$ values in TLC experiments. The pink pigments observed in the TLC-separated indigo solution and in the bacterial extracts also had the same mobilities.

(4) The purified blue bacterial pigment had an identical visible absorption spectrum to indigo.

(5) The solubility characteristics of the unpurified bacterial pigment and indigo were very similar in a wide range of different solvents.

(6) Proton NMR spectroscopy suggested that both the blue and pink pigments were based on indole, and resonance patterns were compatible with the structures of indigo and indirubin for the blue and pink bacterial pigments respectively.

The formation of indigo by Rhodococcus sp. ATCC 21145 was not demonstrated under the defined conditions although the RNA dot blot analysis suggested that the pigment-forming gene was being transcribed in Rhodococcus. This may be due to the low level of activity of the gene at the single-copy level or possibly due to the 
rapid transformation of the pigment into another product by Rhodococcus enzymes, preventing accumulation of the pigment.

Indigo production by $E$. coli containing cloned genes from Pseudomonas spp. has been used as an indicator for expressed aromatic dioxygenase genes from a wide variety of pathways (Eaton \& Timmis, 1986; Ensley $e t$ al., 1982; Irie et al., 1987; Tan \& Mason, 1990; Zylstra et al., 1988), although none of these authors reported the observation of pink as well as blue components in the bacterial pigment. The production of indigo suggests that the enzyme encoded by the pigment-producing Rhodococcus gene was an aromatic dioxygenase. These enzymes are important components of pathways in the degradation of aromatic, xenobiotic compounds and in the biosynthesis of useful products, such as salicylic acid from naphthalene (Ensley et al., 1982). Rhodococcus spp. display great metabolic diversity and are capable of degrading a wide range of aromatic compounds although the exploitation of their potential applications in this area has hardly begun. The ability to produce indigo may be a useful tool in the search for other Rhodococcus genes encoding aromatic dioxygenases, or even whole operons. The function and substrate range of this proposed aromatic dioxygenase from Rhodococcus sp. ATCC 21145 , which causes indigo production in $E$. coli, has not yet been established although it was described in a patent (Raymond, 1971) for the production of hydroxyphenylketobutyric acids by the microbial oxidation of naphthalene.

\section{References}

AibA, H., Adhya, S. \& DE Crombrugghe, B. (1981). Evidence for two functional $\mathrm{gal}$ promoters in intact Escherichia coli cells. Journal of Biological Chemistry 256, 11905-11910.

Botsford, J. L. \& DEMoss, R. D. (1971). Catabolite repression of tryptophanase in Escherichia coli. Journal of Bacteriology 105, 303312 .
ChUng, C. T. \& Miller, R. H. (1988). A rapid and convenient method for the preparation and storage of competent bacterial cells. Nucleic Acids Research 16, 3580.

Eaton, R. W. \& Timmis, K. N. (1986). Characterization of a plasmidspecific pathway for catabolism of isopropyl benzene in Pseudomonas putida RE204. Journal of Bacteriology 168, 123-131.

ENSLEY, B. D., GibSON, D. T. \& LABORDE, A. L. (1982). Oxidation of naphthalene by a multicomponent enzyme system from Pseudomonas sp. strain NCIB 9816. Journal of Bacteriology 149, 948-954.

HART, S., KIRBY, R. \& Woods, D. R. (1990). Structure of a Rhodococcus gene encoding pigment production in Escherichia coli. Journal of General Microbiology 136, 1357-1363.

HART, S. \& WoODS, D. R. (1992). Construction of an insertionalinactivation cloning vector for Escherichia coli using a Rhodococcus gene for indigo production. Journal of General Microbiology 138, 205209.

HiLl, R. T., HART, S. L., Illing, N., KIRBY, R. \& WoOdS, D. R. (1989). Cloning and expression of Rhodococcus genes encoding pigment production in Escherichia coli. Journal of General Microbiology 135, $1507-1513$.

IrIE, S., Shiral, K., DoI, S. \& YorifujI, T. (1987). Cloning of genes encoding oxidation of benzene in Pseudomonas putida and their expression in Escherichia coli and P. putida. Agricultural and Biological Chemistry 51, 1489-1493.

Maniatis, T., Fritsch, E. F. \& Sambroox, J. (1982). Molecular Cloning: A Laboratory Manual. Cold Spring Harbor, New York: Cold Spring Harbor Laboratory.

MiLLER, J. H. (1972). Experiments in Molecular Genetics. Cold Spring Harbor, New York: Cold Spring Harbor Laboratory.

Pardee, A. B., JaCOB, F. \& MONOD, J. (1959). The genetic control and cytoplasmic expression of inducibility in the synthesis of $\beta$-galactosidase by Escherichia coli. Journal of Molecular Biology 1, 165-178.

RAYmond, R. L. (1971). Hydroxy-phenol- $\alpha$-ketobutyric Acids. United States Patent Office. Patent no. 3392846.

TAN, H.-M. \& Mason, J. R. (1990). Cloning and expression of the plasmid-encoded benzene dioxygenase genes from Pseudomonas putida ML2. FEMS Microbiology Letters 72, 259-264.

VIEIRA, J. \& Messing, J. (1982). The pUC plasmids, an M13mp7derived system for insertion mutagenesis. Gene 19, 259-268.

W ARD, D. F. \& YUDKIN, M. D. (1976). Mutations in Escherichia coli that relieve catabolite repression of tryptophanase synthesis. Tryptophanase promoter-like mutations. Journal of General Microbiology 92, 133-137.

Zabeau, M. \& Stanley, K. (1982). Enhanced expression of cro- $\beta$ galactosidase fusion proteins under the control of the $P_{\mathrm{R}}$ promoter of bacteriophage lambda. EMBO Journal 1, 1217-1224.

Zylstra, G. J., McCombie, W. R., Gibson, D. T. \& Finette, B. A. (1988). Toluene degradation by Pseudomonas putida F1: genetic organization of the tod operon. Applied and Environmental Microbiology 54, 1498-1503. 